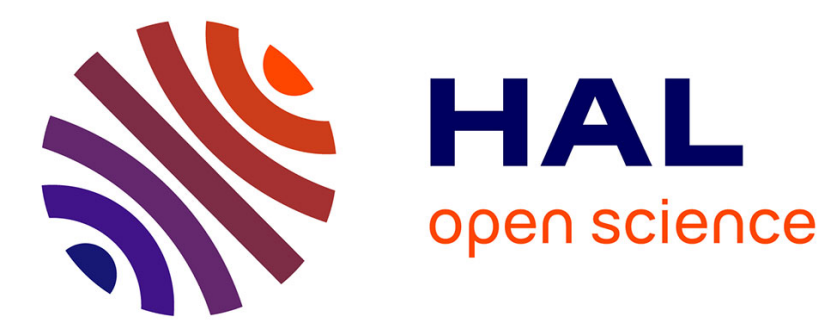

\title{
Designing for physically disabled users: benefits from human motion capture - a case study
}

\author{
Guillaume Thomann, Cécile Magnier, François Villeneuve, Richard
}

Palluel-Germain

\section{- To cite this version:}

Guillaume Thomann, Cécile Magnier, François Villeneuve, Richard Palluel-Germain. Designing for physically disabled users: benefits from human motion capture - a case study. Disability and Rehabilitation: Assistive Technology, 2016, pp.695-700. 10.3109/17483107.2015.1042078 . hal-01176137

\section{HAL Id: hal-01176137 \\ https://hal.science/hal-01176137}

Submitted on 21 Jul 2015

HAL is a multi-disciplinary open access archive for the deposit and dissemination of scientific research documents, whether they are published or not. The documents may come from teaching and research institutions in France or abroad, or from public or private research centers.
L'archive ouverte pluridisciplinaire HAL, est destinée au dépôt et à la diffusion de documents scientifiques de niveau recherche, publiés ou non, émanant des établissements d'enseignement et de recherche français ou étrangers, des laboratoires publics ou privés. 


\title{
Designing for Physically Disabled Users: the Benefits of Human Motion Capture - A Case Study
}

\author{
Guillaume Thomann ${ }^{1}$, Cécile Magnier ${ }^{1}$, François Villeneuve ${ }^{1}$, Richard Palluel-Germain ${ }^{2}$ \\ ${ }^{1}$ Laboratory of Sciences for Design, Optimisation and Production (G-SCOP), 46 avenue Félix \\ Viallet, Univ. Grenoble Alpes, G-SCOP, F-38000 Grenoble, France \\ CNRS, G-SCOP, F-38000 Grenoble, France \\ ${ }^{2}$ Psychology and NeuroCognition Laboratory (LPNC), Université Pierre Mendes France, BP \\ 47, 38040 Grenoble Cedex 9, France
}

\begin{abstract}
Purpose:

The aim of this study was to improve the design of an interface to help disabled children to play a musical instrument. This involved integrating human motion capture in the design process.

Method:

The participant performed twenty pointing movements towards four selected locations. Three one-way analyses of variance (ANOVA) were performed in order to determine the most efficient input location. For each button position, (1) the Reaction Time (RT), (2) the Movement Time and (3) the spatial variability of the movements were compared.

Results:

The results obtained for RT and MT revealed that one of the positions was the best button location for producing efficient movements.

Conclusions:
\end{abstract}

As the case study showed, combining a 3D motion capture system with statistical analysis helped the designers to develop their design methodology and make crucial choices. 
Keywords: design method, pointing task, human motion kinematics, motor skill

\section{Main Text}

\section{Introduction}

Assistive technologies aim to help disabled people benefit from a more independent life style. Designing for disabled users differs from designing for valid users since the designers cannot rely on their own experience as users [1]. In other words, they cannot play the role of the disabled users, even if they try to recreate their life conditions. For designing assistive equipment a specific design strategy has to be discussed. For example in [2], the designers' experience with severely disabled young people helped them to refine the design strategy for special switch systems and an interface enabling the control of powered wheelchairs, computers, communication aids and environmental control systems. Currently, User Centred Design (UCD) is widely used in the field of assistive technology. This design approach has been codified in an ISO standard [3]. It targets the adaptation of the product to the user through user involvement. Users do not only test advanced prototypes at the end of the design process but are highly involved throughout [4]. In a UCD approach, the users are widely observed by the designers. The most common means of observation are direct observation and video recording. In this line of research, video recording is considered an effective technique in the UCD context [5] [6].

In our study, a disabled user was provided with an interface in order to take part in a music activity with other musicians. The user's upper-limb performance was measured using kinematic parameters such as speed, trajectory and accuracy [7] [8]. It should be noted that during a group-based music activity, reaction time and movement speed constitute the essential parameters for anticipating the right moment to play. Reaction time and movement 
time are thus useful parameters for designing an instrument for playing music [9]. Furthermore, in activity involving repeated movements we may reasonably assume that a high level of variability suggests a number of poorly performed movements. The aim of this study was to use motion capture in order to measure such parameters and explore how this technique can benefit user design.

With this in mind, human movement kinematics seemed to be a promising avenue to explore. This is the scientific discipline concerned with the motion of human bodies based on psychological, neurophysiological and mechanical aspects. It includes both empirical work and research on movement modelling. Following our literature review, we found that human movement kinematics has given rise to a law that is widely used by designers: Fitt's law [10]. Fitts' law is a model that predicts the time required to move a finger from an initial position to a specific target. The pointing time depends on both the target size (the smaller the target, the longer the pointing time) and the distance from the initial position to the target (the further the target, the longer the pointing time). In its initial formulation, Fitt's law was only applied to the visually guided movement of a healthy person's finger. However, it has also been used to evaluate a custom-tailored bedside computer access solution for a 20-year old individual with quadriplegia [11]. Two months after introducing the access solution, the researchers measured its impact using a 2-dimensional Fitt's Law test and questionnaires. The analysis showed that the patient learned single-switch typing with a throughput of $1.03 \mathrm{bits} / \mathrm{s}$ and a targeting accuracy of $87.5 \%$.

This model is now widely used in the field of Human-Computer Interaction (HCI) both for valid and impaired users. There are two ways to use Fitt's law in HCI. The first is to predict the time needed by the user to move an input device such as a mouse to a button on a graphical interface. This helps with the selection of icon positions and sizes [12]. The second 
way to use Fitts' law in HCI is to evaluate different pointing devices such as a mouse and a joystick. This contributes to selecting the most efficient pointing device [13].

In this paper, we report the results of a pilot study with a 17-year old girl who enjoys playing music despite her physical disabilities. To become a fully independent musician, she needed an adapted interface for accessing her instrument.. The design a special user interface for her, i.e. a hand-activated button controlling an existing motorized drumstick was decided. Since speed and timing are so important for making music [14], simply establishing a qualitative assessment of her performance using a special kind of input was not enough. We also needed to define the most efficient special device with precise quantitative measurements. Thus, we compared different input locations and studied movement kinematic materials, parameters and statistical methods. Four different positions were tested. These were labelled according to the sagittal plane of the participant: 'extreme right', 'right', 'front' and 'left'. The participant performed twenty pointing movements towards four selected locations. This task mainly reflected the way she played her instrument, i.e. by reacting to stimulus from her music teacher.

As she performed these movements, her hand was recorded via a $3 \mathrm{D}$ motion measurement system. The collected data was processed to obtain (1) the reaction time, (2) the movement time, and (3) the endpoint accuracy (the distance between the endpoint and the mean endpoint of the condition). In order to determine the most efficient input location, statistical analysis comparing the four locations was performed on these three parameters. During the case study, researchers were able to observe the influence of human movement kinematics (materials and methods) on the designers' assistive technology decisions. 


\section{Method}

\subsection{Participant}

One teenage girl participated in this study. She was seventeen years old, had no independent mobility and used an electric wheelchair controlled by her right hand. Her health condition also required her to wear corrective lenses. She attended a special school for disabled teenagers. The task and the material for the experiment were familiar to her since she had already used similar devices in the past at her school.

\subsection{Apparatus}

The general configuration of the experimental room is presented in Figure 1. We used a 3D motion measurement system to record the hand position. More specifically, we used the ZEBRIS CMS10, which is a system based on ultrasonic triangulation [15]. Small adhesive transmitters called markers were attached to the participant's hand. These sent ultrasonic pulses to three microphones located on a floor stand. Data acquisition was based on a recording of the three dimensional spatial position of each marker every $10 \mathrm{~ms}$.

\section{Insert figure 1 about here}

\subsection{Procedure}

All sessions were conducted in a quiet room. Two CMS10 markers were positioned on the participant's right hand as shown in figure 2. A 'Big Buddy' yellow contactor (made by the company Suppleance - http://www.suppleance-78.com/fr/) was positioned on the participant's wheelchair table. This contactor is a common solution for enabling disabled people to use computers. Upon receiving a 'go' signal, the participant was asked to point the button with her dominant hand as quickly and accurately as possible. As shown in figure 3, four different button positions along the participant's sagittal axis were tested. It is important to note that the 
'extreme left' position was discarded since the participant could not perform movements in this direction.

\section{Insert figure 2 about here \\ Insert figure 3 about here}

In total, 80 trials were performed during two sessions separated by about 15 minutes. In each session, the participant was first asked to produce 10 trial movements to the 'right' position, 10 to the 'extreme right' position, 10 to the 'front' position and 10 to the 'left' position. Twentytwo trials were not analysed due to technical problems. The participant used a specific starting hand position throughout all the trials. The distance $\mathrm{d}=20 \mathrm{~cm}$ between the hand's initial position $(\mathrm{x}, \mathrm{y})=(0,0)$ and the button was the same for each button position.

\subsection{Data analysis}

Figure 4 illustrates the three parameters considered. We analysed the (1) Reaction Time (RT), i.e. the time between the 'go' signal and the beginning of the movement, (2) The Movement Time (MT), i.e. the time between the beginning and the end of the movement and (3) Endpoint Accuracy (EA), i.e. the distance between each endpoint and the mean endpoint for each condition.

\section{Insert figure 4 about here}

One of the 'markers' was dedicated to RT recording. At first, this marker was covered and was unable to operate. One of the experimenters said 'go' while uncovering this 'marker' so that the 'go' signal was identified when that marker was uncovered. Movement onset was defined as the time when a marker's tangential velocity first exceeded $6 \mathrm{~cm} / \mathrm{s}$. Likewise, the end of the movement was defined as the first time the tangential velocity fell below a $6 \mathrm{~cm} / \mathrm{s}$ threshold. Finally, the endpoint was the position on an $(\mathrm{x}, \mathrm{y})$ plane marker at the end of the movement. 
For each of the three parameters (Reaction Time, Movement Time and Endpoint Accuracy), any values whose mean exceeded two standard deviations of the condition (i.e. position of the target) were excluded [16]. Four trials were excluded from the initial number (58 in total).

\subsection{Statistical analysis}

This was critical in our case since the movements of disabled people tend to have a high level of variability when they perform repetitive tasks. It was also beneficial owing to the limited number of trials performed. Indeed, we believe that inferential statistics are central for this research.

For choosing the best head control system for people who cannot use a keyboard, some researchers suggested comparing three methods for speed and accuracy using a single subject design for nine individuals with disabilities. Visual inspection of the researchers' data revealed that the subjects obtained higher scores when using two of the three interfaces. However, as a follow-up test, an analysis of variance for repeated measurements showed either a significant difference or no difference using these interfaces [17].

This leads us to believe that statistical methods used in human movement kinematics, such as analysis of variance, can benefit designers, especially in the field of assistive devices.

\section{Results}

A one-way analysis of variance (ANOVA) comparing the reaction time for each button position was performed with repeated measurements in relation to the button's position. Howell (2008) provides an overview of the basics of inferential statistics [18]. For this case study, it is important to note that in the following form: $\mathrm{F}(\mathrm{df} 1, \mathrm{df} 2)=\mathrm{x}, p=y \quad$ (1) $\mathrm{F}$ indicates that an ANOVA was performed, (2) df1 is the degree of freedom for the conditions, (3) df2 is the degree of freedom for the trials, (4) $\mathrm{x}=$ is the $\mathrm{F}$ value, (5) y is the probability of obtaining 
a test statistic at least as extreme as the one that was actually observed, assuming that the null hypothesis is true, i.e. differences between groups can only be explained by error.

\title{
3.1 Reaction time
}

From the designer's perspective, the results suggest that at least one button position was more efficient than at least one other button position. As shown in table 1, since the 'extreme right' position had a lower mean reaction time, standard deviation and standard error, the extreme right position could be considered as the most efficient button position. Furthermore, the boxplot representation gives important additional information (figure 5). The median of the front position was lower than the median of the extreme right position, which was not the case for the mean reaction time.

\author{
Insert table 2 about here \\ Insert figure 5 about here
}

\subsection{Movement time}

A one-way analysis of variance (ANOVA) comparing the movement time for each button position was performed: $\mathrm{F}(3,50)=0.70, p=0.55$.

Because of the $p$ value, there was no evidence that the button position had a significant effect on movement time. From the designer's perspective, this meant that the analysis of this parameter did not reveal whether or not a given button position was more efficient than the others.

As shown in figure 6, the median, quartiles and extreme values of the extreme right position are comparatively better than the other positions. Without this statistical analysis of variance, the designer would have concluded that the extreme right position was the best. However, the statistical analysis indicated that no conclusion could be drawn from the results, in spite of this clearly favorable position. 


\subsection{Endpoint accuracy}

A one-way analysis of variance (ANOVA) comparing the distance between each endpoint and the mean endpoint for each button position was performed: $\mathrm{F}(3,50)=4.2, p=0.01$. From a statistical point of view, the results showed that the button position had a significant effect on the spatial variability of the endpoint. From the designer's perspective, it showed that one or several button positions were significantly more efficient than one or several other button positions.

As shown in figure 7, since the extreme right position had the lowest mean and the lowest variability, the 'extreme right' position could be considered as one of the most efficient button positions.

\section{Insert figure 7 about here}

\subsection{Task Order effect}

In this study, the order of the tasks was not fully randomized. In order to control for possible fatigue (decreased accuracy during the tasks) or training effect (increased accuracy), endpoint accuracy was compared between the first and the second session. Thus, an A 2 X 2 (Position $\mathrm{X}$ Session) ANOVA analysis of variance tested the effects of the position and session number on the endpoint accuracy.

As stated before, the button position had a significant effect on endpoint accuracy.

There was no significant session effect: $F(1,46)=0.016, p=0.9$. The interaction between the two factors was qualified as: $\mathrm{F}(3,46)=1.2, \mathrm{p}=0.33$.

This suggests that the position had no influence on the result in either the first or second session. 
Endpoint accuracy in sessions one and two was also compared. The interaction between the two factors was qualified as: $\mathrm{F}(18,24)=1.7, \mathrm{p}=0.12$, indicating that the position effect was the same throughout the different trials. There was no significant change in endpoint accuracy over time.

\section{Conclusion}

In this study, we explored a method to analyse motion in order to support designers' decisionmaking. Materials and methods associated with human movement kinematics were used for this purpose.

The Zebris 3D motion measurement system proved to be an efficient tool. It provided the designers with more information than the usual video analysis performed. Reaction time, movement time and endpoint accuracy were reliably accessible to the designers.

Furthermore, inferential statistical analysis also proved to be an efficient tool. It should be noted that designing for this type of user is challenging: disabled people tend to have highly varying movements and only a limited number of trials were possible. In this specific context, comparing the means of different conditions in order to deduce the most efficient device location was highly risky: the difference between means does not necessarily reflect a difference between the fulfilling of different conditions.

Combining the 3D motion measurement system with statistical analysis helped the designers to identify the most efficient button position.

Two out of the three parameters studied allowed the designers to deduce that the 'extreme right' position of the button was one of the most efficient button locations. 


\section{Discussion}

As explained in the procedure section, the researchers' intention was to control the movement distance so that this distance was the same throughout all the trials. It was decided (1) that the participant would start all trials from the same hand position and (2) that the distance between the initial hand position and the target button would be the same for the four button positions. However, the trials revealed that the participant was not able to control her initial hand position. Figure 8 represents the starting point and endpoint of each trial. In this figure, we can see that the positions vary greatly. The positions of the white dots suggest that the initial position depends on the target position. This also suggests that the participant tried to take a shortcut by choosing an initial position that was closer to the target.

\section{Insert figure 8 about here}

How did this affect results? Even if the participant's behaviour was different from that expected, the tasks she performed during the trials imitated her music-playing activity in her real environment. In the real world, the participant would be free to take such shortcuts. However, for future studies we must keep in mind that the participant can only take shortcuts based on advance knowledge of where to point her hand. Consequently, the study described can only be validated under the following conditions: when there is only one button at a time that is visible in advance or when there are several buttons at a time and the participant is able to anticipate which button she will have to point to.

For this latter case, i.e. if the user has several buttons at the same time and is able to anticipate which one to use (like singing a song they have memorised and been trained to sing), then another procedure regarding the initial hand position and the block organisation will be needed.

In other words, the task the participant is asked to perform will have to be adjusted. However, the way the movement was analysed in this study could apply to many situations, such as 
designing devices for activities other than music-playing or designing for users with other physical disabilities.

This research work could be exploited as a specific experimental phase of an AT design process for an individual. The aim of User Centred Design is to improve product usability. This methodology is based on five technical points that the project design must take into account: knowledge of end users (tasks, environments), active user participation (needs and requirements), appropriate sharing of functions between users and technologies, an iterative approach to design and, finally, the involvement of a multidisciplinary team. The experiment described above is fully in accordance with these points. More specifically, Ability-Based Design is a specialised concept able to support this experiment because it attempts to shift the focus of accessible design from disability to ability. As shown in our research, the central focus of the experiment described is ability.

\section{Future prospects}

As stated in the data analysis section, the 'go' signal time was given orally by one of the experimenters. It was calculated from an additional marker that was covered and uncovered by that experimenter. It is possible to design a technical solution based on an electronic buzzer that would be connected to the 3D movement system and send a signal when the 'go' signal is issued.

As explained in the data analysis section, the end of the movement was calculated using the speed of the hand. The user experienced a rebound effect when impacting the button. This makes it challenging to define the end of the movement in a reliable manner. In further studies, it would be better to find a technical solution to connect the button to the 3D movement system and send a signal to the $3 \mathrm{D}$ movement system when it is activated. 


\section{Acknowledgements}

The authors wish to thank the disabled user for her involvement in the experiment and many discussions with the students and researchers. They also wish to thank the students and the technician who helped to install and calibrate the ZEBRIS system and perform the experiment.

\section{Declaration of interest statement}

The authors report no declaration of interest

\section{References}

[1] Cardoso C, Clarkson PJ. Simulation in user-centred design: helping designers to empathise with atypical users. Journal of Engineering Design 2012;23(1):1-22

[2] Thornett CEE. Designing special switches and control systems for multiply handicapped young people - a problem - led approach. Journal of Medical Engineering \& Technology $1990 ; 14(3): 87-91$

[3] NF EN ISO 9241-210. Human-centred Design Processes for Interactive Systems. International Organization for Standardization 2011

[4] Nielsen J. Usability Engineering. Academic Press, Boston, 1993. 358p.

[5] Brun-Cottan F, Wall P. Using video to re-present the user. Communications of the ACM $1995 ; 38(5), 61-71$

[6] Gulliksen J, Lantz A, Boivie I. User Centered Design - Problems and Possibilities. SIGCHI Bulletin 1999;31(2), 25-35 
[7] Dido G, Peter HW. Use of virtual reality in rehabilitation of movement in children with hemiplegia - A multiple case study evaluation. Disability and Rehabilitation 2012;34(7):593604

[8] Covarrubias M, Gatti E, Bordegoni M, Cugini U, Mansutti A., Improving manual skills in persons with disabilities (PWD) through a multimodal assistance system. Disability and Rehabilitation: Assistive Technology 2014 Jul;9(4):335-43

[9] Bock O, Arnold K. Motor control prior to movement onset: preparatory mechanisms for pointing at visual targets. Experimental Brain Research 1992;90(1):209-216

[10] Fitts P., The information capacity of the human motor system in controlling the amplitude of movement. J. Exper. Psychol. 1954;47(6):381-391

[11] Blain S, McKeever P, Chau T. Bedside computer access for an individual with severe and multiple disabilities: A case study. Disability and Rehabilitation: Assistive Technology 2010;5(5):359-369

[12] Lepicard G, Vella F, Vigouroux N, Rigolleau B, Chautard D, Pucheu E. The Virtual Paddle: An Universal Interaction for Accessible Video Games. Universal Access in HumanComputer Interaction. Applications and Services. Lecture Notes in Computer Science 2007;4556:677-686

[13] MacKenzie S, Jusoh J. An Evaluation of Two Input Devices for Remote Pointing. Proceedings of the Eighth IFIP Working Conference on Engineering for Human-Computer Interaction, Springer, Heidelberg, Germany. 2001:235-249

[14] Charles D, James KB, Stein RB. Rehabilitation of musicians with upper limb amputations. Journal of Rehabilitation Research and Development 1988;25(3):25-32

[15] Product information CMS10 [Internet]. [Cited 2014 Nov 4]. Available from http://www.zebris.de/english/pdf/e_Technical_Data_CMS10.pdf 
[16] Field AP. Discovering statistics using SPSS. London, England : SAGE, 2009

[17] Angelo J, Deterding C, Weisman J. Comparing Three Head-Pointing Systems Using a Single Subject Design, Assistive Technology 1991;3(2):43-49

[18] Howell DC. Fundamental statistics for the behavioral sciences $\left(6^{\text {th }}\right.$ ed.). Belmont, CA: Wadsworth 2008 
Tables with captions

\begin{tabular}{|l|c|c|c|c|c|c|}
\cline { 2 - 7 } & $\begin{array}{c}\text { Nbr of } \\
\text { trials }\end{array}$ & $\begin{array}{c}\text { Mean reaction } \\
\text { time }(\mathrm{ms})\end{array}$ & $\begin{array}{c}\text { Std. Deviation } \\
(\mathrm{ms})\end{array}$ & $\begin{array}{c}\text { Std. Error } \\
(\mathrm{ms})\end{array}$ & $\begin{array}{c}\text { Minimum } \\
(\mathrm{ms})\end{array}$ & $\begin{array}{c}\text { Maximum } \\
(\mathrm{ms})\end{array}$ \\
\hline Left & 15 & 275.3 & 118.9 & 30.7 & 90 & 440 \\
Front & 16 & 179.4 & 92.2 & 23.0 & 20 & 350 \\
Right & 12 & 187.5 & 114.9 & 33.1 & 40 & 450 \\
Extreme right & 11 & 164.5 & 60.2 & 18.1 & 90 & 260 \\
\hline Total & 54 & 204.8 & 107.6 & 14.6 & 20 & 450 \\
\hline
\end{tabular}

Table 1. Reaction time of the different groups 
Figures with captions

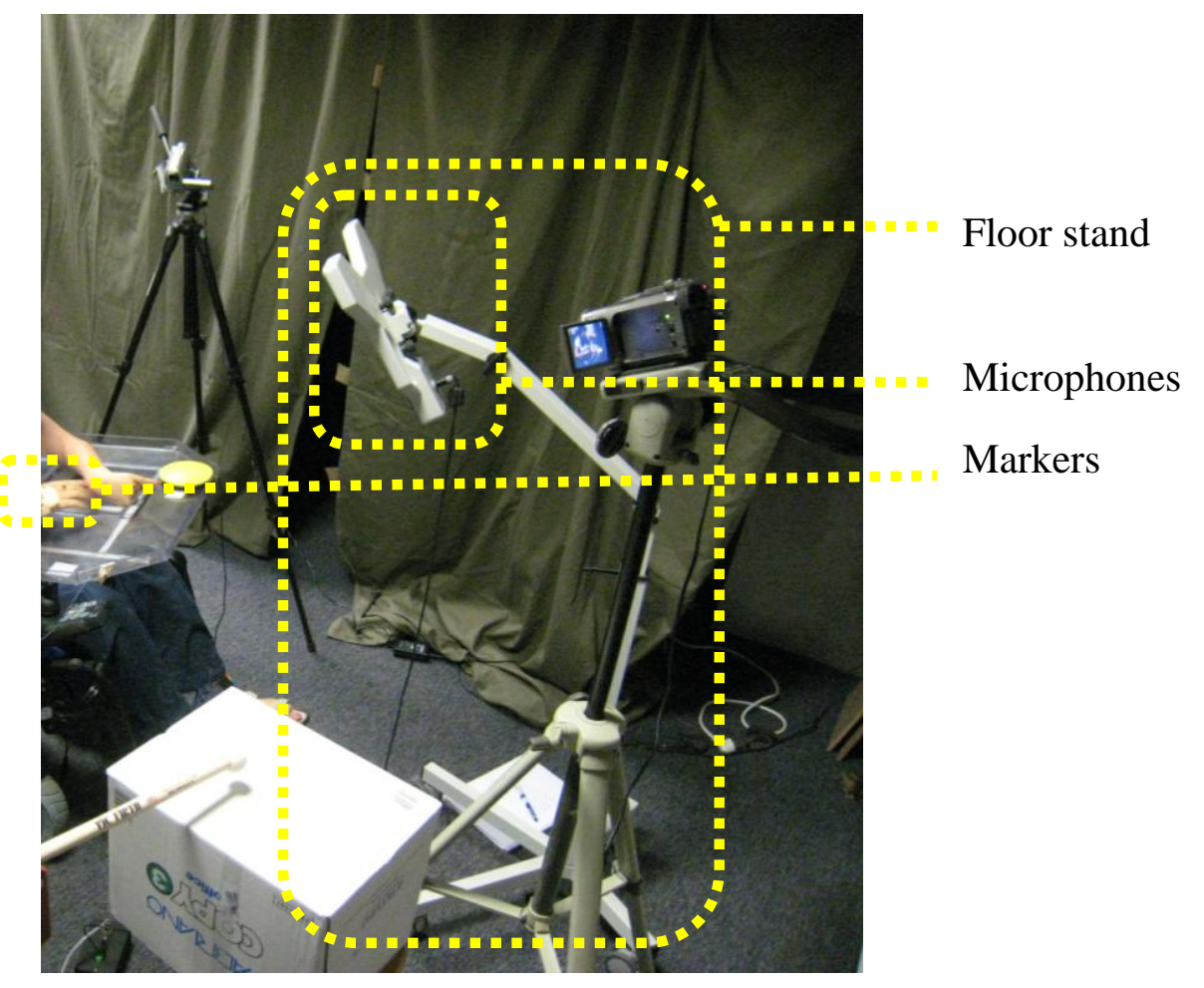

Figure 1. Experimental room set-up 


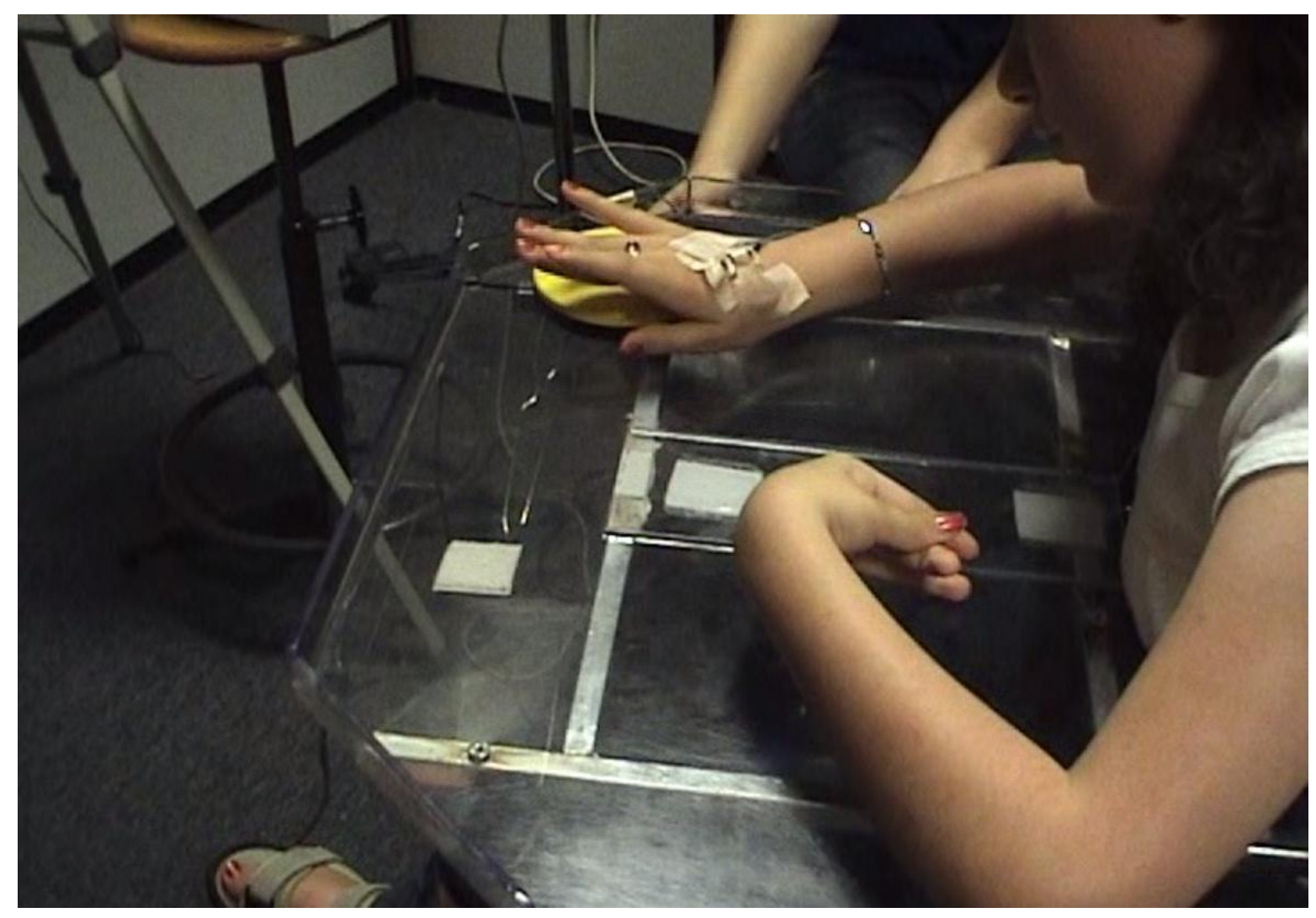

Figure 2. Two CMS10 markers positioned on the participant's right hand

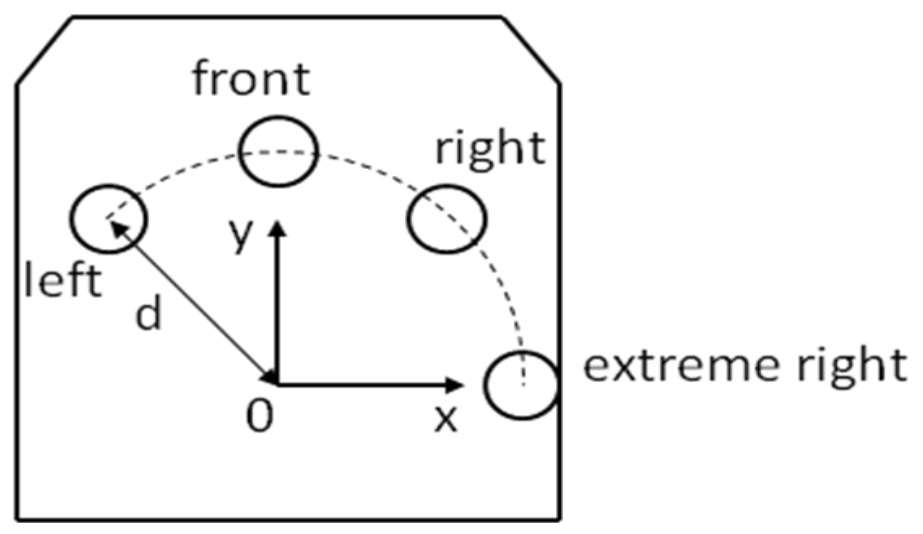

Figure 3. Location of the four different button positions tested in this study 


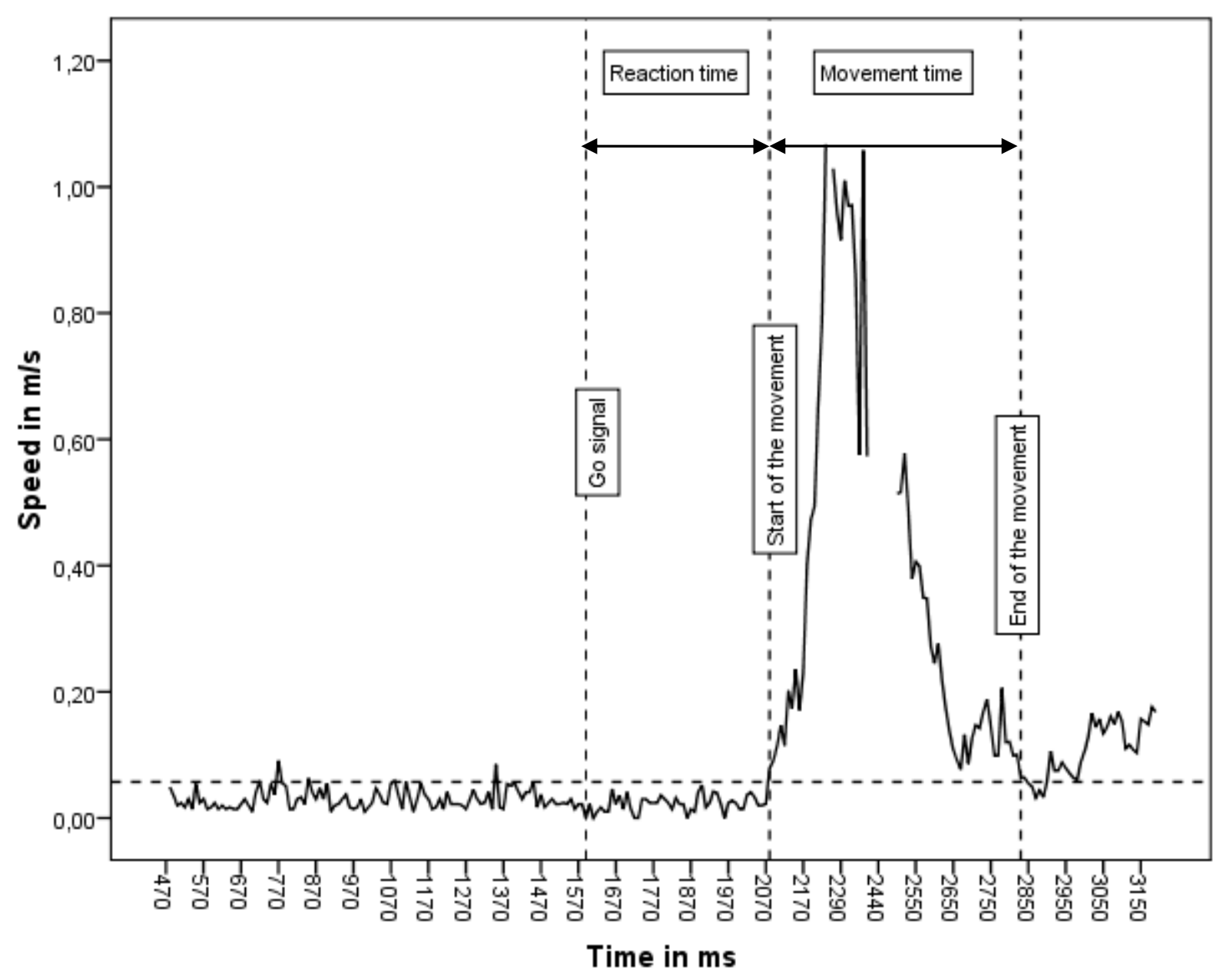

Figure 4. Changes to hand speed over time during one of our trials.

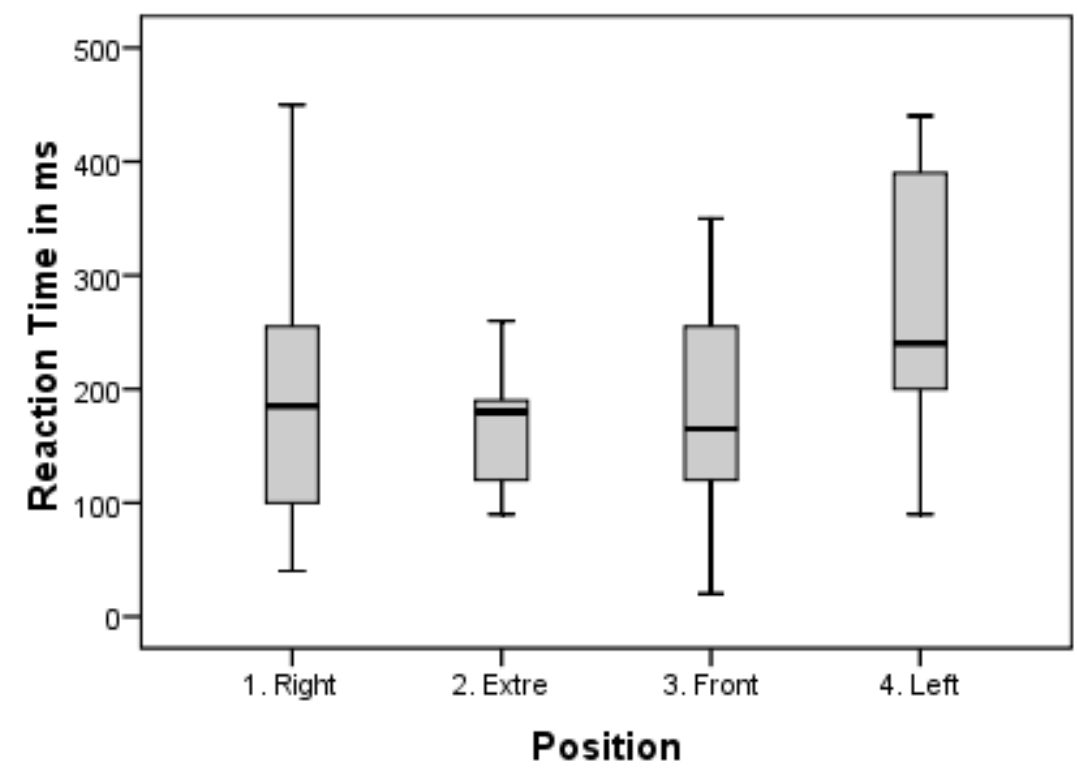


Figure 5. Boxplot representation (each box shows the median, quartiles and extreme values within a category) of the reaction time for each button position.

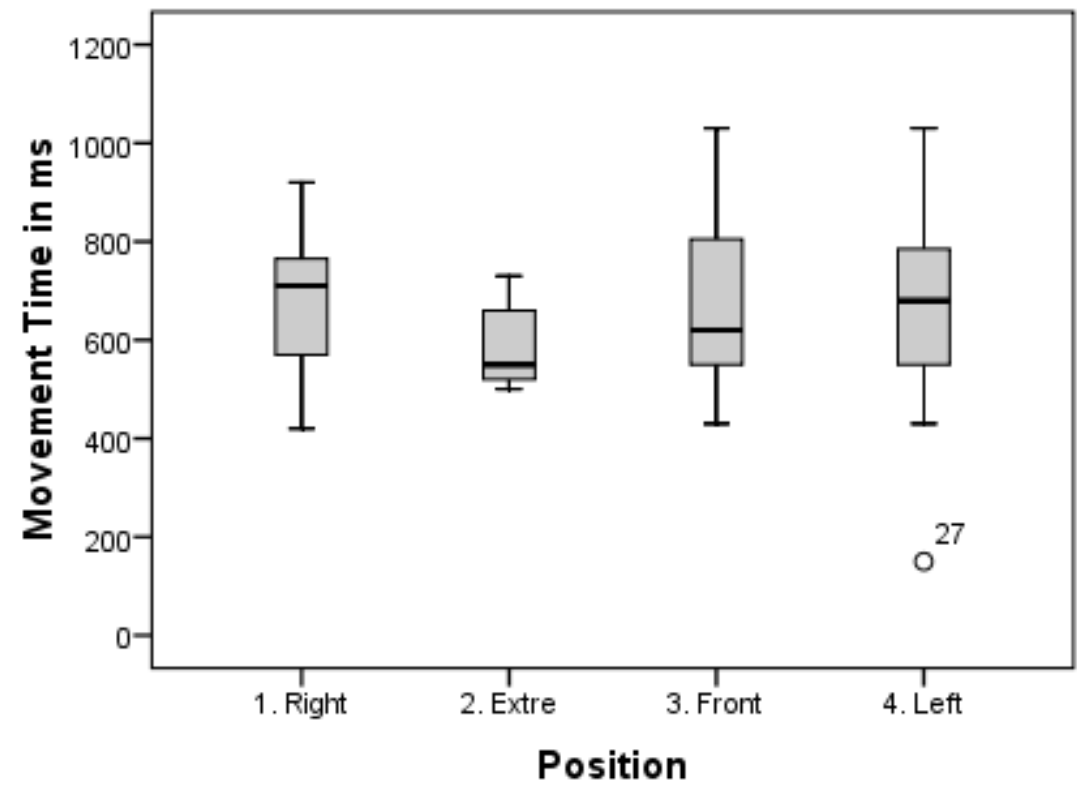

Figure 6. Boxplot representation (each box shows the median, quartiles and extreme values within a category) of the movement time for each button position.

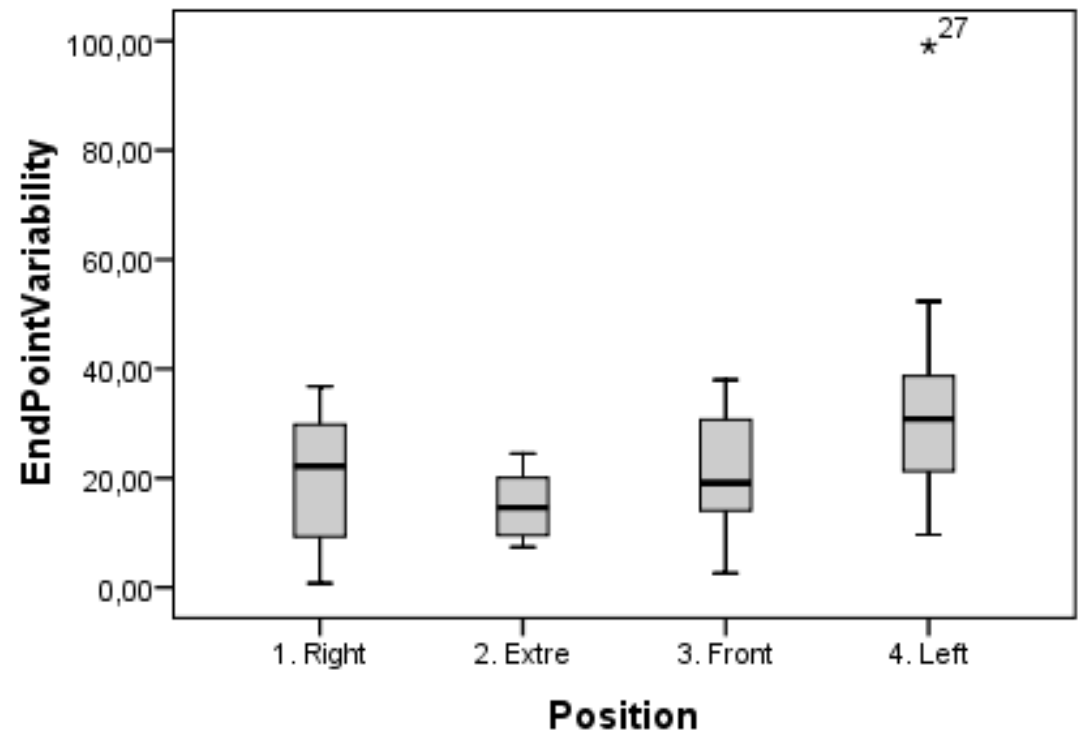

Figure 7. Boxplot representation of Endpoint Variability (distance from the endpoint to the mean endpoint of the condition) for each button position 


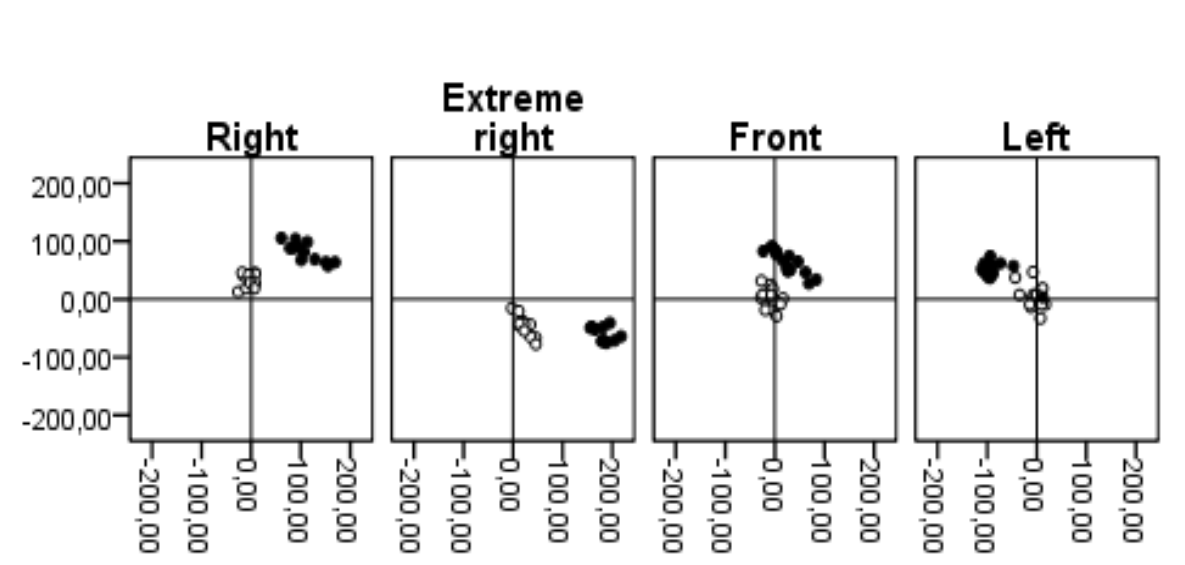

Figure 8. For each button position: representation of the starting point (white dots) and endpoint (black dots) of all trials 